This item was submitted to Loughborough's Research Repository by the author.

Items in Figshare are protected by copyright, with all rights reserved, unless otherwise indicated.

\title{
Figures of the global: Mobility journeys of international school pupils
}

\section{PLEASE CITE THE PUBLISHED VERSION}

https://doi.org/10.1002/psp.2305

\section{PUBLISHER}

Wiley

\section{VERSION}

AM (Accepted Manuscript)

\section{PUBLISHER STATEMENT}

This is the peer reviewed version of the following article: Cranston, S., (2020) Figures of the global: Mobility journeys of international school pupils. Population, Space and Place, 26(6): e2305, which has been published in final form at https://doi.org/10.1002/psp.2305. This article may be used for non-commercial purposes in accordance with Wiley Terms and Conditions for Use of Self-Archived Versions

\section{LICENCE}

CC BY-NC-ND 4.0

\section{REPOSITORY RECORD}

Cranston, Sophie. 2020. "Figures of the Global: Mobility Journeys of International School Pupils". Loughborough University. https://hdl.handle.net/2134/11335577.v1. 
Figures of the Global: Mobility Journeys of International School Pupils

\section{Abstract:}

Existing accounts of youth global mobility frame this as an experience which is out of ordinary, through which young people acquire social and cultural capital. This paper focuses instead on how young people in international schools in England understand their experiences of global mobility. It utilises an innovative methodology where participants were asked to design cartoons about global citizenship. Bringing together literatures on journeys and becomings, the paper examines how the global is represented by young people in the cartoons through scenes and characters. By looking at how the characters interact with the scenes and characters, the paper argues that these act as representations of space-time in international school pupil's global mobility journeys. Through this, the paper demonstrates how this group of mobile young people represent global mobility as a normal experience, which raises wider geographical questions about the intersections between youth identity and mobility.

\section{Acknowledgments:}

Thanks to James, Ruth and Matej for their work on this special issue and their support for this paper, as well as the reviewers who provided constructive feedback. Thanks also to the students on GYC325 'Geographies of Transnational Mobility and Diaspora' for their discussions on journeys which has inevitably helped shape hone the ideas presented in this paper. And of course, thanks to the teachers and pupils at the two international schools for facilitating this research. 


\section{Introduction}

Transnational mobility is increasing becoming a constitutive element of young people's lives (Cheung Judge et al, SI intro). There is well documented demographic shift that highlights that spending time abroad, whether it be living internationally with family, travel, work or study is either aspirational or realised for young people globally (Robertson, Harris and Baldassar, 2017). Hopkins and Alexander (2010), highlighting a need to mainstream the geographies of young people in human geography, argued that this involves the 'upscal[ing of] young people's geographies to focus on global, transnational...rather than simply exploring key facets of everyday local negotiations' (p.142; see also Ansell 2009). We can usefully extend this argument to a focus on mobilities. It is increasingly important to specifically examine how mobilities have meaning for young people and the impact that this has upon geographical understandings of youth, identity and mobility.

However, an issue in thinking about the transnational mobility of young people to date has been a combination of methodological nationalism (Wimmer and Glick Schiller, 2002) and the theoretical dominance of Bourdieu's capital. The limited amount of scholarship which looks at young people and mobility generally focus on place-based accounts which privilege stasis and see mobility as exceptional or distinctive (Barker et al., 2009; Dobson, 2009; White et al., 2011; Bunnell, 2016). Here the global mobility of young people is theorised as the gaining of an experience that others do not have, an experience that can be leveraged as capital for future advantage and social mobility (c.f. Bourdieu). For example, research on international youth volunteering shows how this form of transnational mobility relates to the formation of cultural capital (examples include Lorimer, 2010; Baillie Smith and Laurie, 2011; Jones, 2011). International student mobility has often been viewed 
from the same perspective (King and Raghuram, 2013). In this way, mobility is discursively produced as an experience which is out of the ordinary, one which acts as distinction or as a rupture in the lifecourse. Analysis focuses not how young people feel about mobility in itself, but the role that this 'different' experience plays.

This paper focuses on providing a different reading of global mobility and young people's lives. It looks at a population of young people for whom mobility is not exceptional-young people in international schools. Globally there has been a welldocumented growth of international schools, with a diversification of type. Hayden and Thompson (2013) outline a three-part typology: type A is the 'traditional' international school that caters to the children of globally mobile parents; type B is the ideological school that's goal is to develop international mindedness; type C, which is the type of school that has seen significant growth, is a for-profit school aimed towards the aspirational middle classes of a local population.

In this paper, I focus on the 'traditional' international school which has a long history in catering for globally mobile children. The reason that these schools were initially set up was to enable the children of missionaries, colonial administrators and businesspeople to live abroad as part of their family unit and/or to maintain a continuity of education between locations. These international schools are associated with the children of people who undertake international work assignments as part of their careers. In the United Kingdom, this is the population that international schools cater towards (Hayden, 2011). Directories list different numbers of international schools in the UK which offer American, French, German curriculums and the International Baccalaureate. All these schools are fee-paying, and the majority offer boarding facilities. 
International school pupils are a distinct population for three reasons. First, international schools are associated with the education of people who, in mobility terms, are a 'privileged elite' in their ability to move around the world, both in pursuit of opportunities and through their ability to afford the often high international school fees (Hayden, 2011). In thinking about 'privileged' migration, the focus of research has either been on adults (e.g. Cranston and Lloyd 2019) or privileged class reproduction through international student mobility (e.g. Beech 2019), though there are a few exceptions (Sander 2016). Second, international schools contain young people who may have had experiences of living in multiple countries and are in the international school system to keep up a continuity of education. The profile of mobility for these young people will differ between individuals, some may have spent a significant amount of time in one location only, while others may have moved between locations as frequently as every second year (Grimshaw and Sears, 2008). Third, as a result of mobility, there are a number of different nationalities and backgrounds within the school (Hayden, Rancic and Thompson, 2000; Kong, 2013). However, despite the differences in mobility patterns between young people in 'traditional' international schools, global mobility either of themselves or others around them is a common shared experience. Young people in international schools therefore provide us with a vantage point for exploring a population where mobility is a normal experience in childhood.

The paper focuses on how young people in international schools characterise global mobility as part of their childhoods. It draws upon research in two international schools in England in 2017 where I asked the school pupils to design a cartoon to the title of 'what I think global citizenship means.' The paper examines the characters used in 68 cartoons, the people, their actions and the landscapes they navigate. 
Through the paper, I argue that these characters act as 'figures of the global,' a way in which the cartoon designers represent what the global looks like to them. Salazar (2017) argues that figures are a way in which mobilities are materialised, acting as both a metaphor and a lived experience for certain kinds of movement. The characters designed in the cartoons act as just this-global mobility is given an image, which can be embodied by young people. The figures therefore act as an analytical tool where we can see how young people interpret the global in relation to their lives. This is important as the global itself is an abstraction (Cheung Judge, 2017), with the images and characters acting as a representation of how we understand the socio-spatiality of the global (Ansell, 2009).

In looking at the figures of the global, the paper illustrates three points. First, the characters undertake a journey through time and space, with the characters changing with and through their mobility. The paper argues that this becomes a way in which the space-time of migration for young people in international schools can be understood. Second, the paper argues that the figures of the global illustrate how global mobility can be an ordinary part of childhood for these young people. Third, the paper concludes by exploring how the space-time of young people can help us take up Ansell's charge to 'look outside the porous boundaries of the locales of childhood' (2009, p. 2004) to explore how framing mobility as normal can have wider implications for how we understand the intersections between mobility and identity. It is to how the paper is theorised that it now turns. 


\section{Space-Time, Journeys and Becomings}

In this section, I look at two ways in which questions of space-time have been researched by geographers - the journey in mobilities literature and becoming in the geographies of children and youth-examining how these can be placed into conversation with one another.

The concept of the 'journey' or 'trajectory' draws upon a wider corpus of research in mobilities, where the journey is used as a methodological tool to follow the trajectories through time and space of individual migrations (Schapendonk and Steel, 2014; Mainwairing and Brigden, 2016; Schrooten, Salazar and Dias, 2016;

Schapendonk et al., 2018). Primarily, within the literature on migration, the journey has been used to upset bi-polar notions of migration and explore the fragmented nature of migration process. For example, Schapendonk and Steel (2014) use the example of Nigerian men migrating to Europe, illustrating transit periods in their migration journeys. They argue that this illustrates multiple points of departure, settlement and destinations for migration, ones which are often produced by the regulatory systems in the locations that they are passing through. This helps us think about the multiple spaces through which migrant journeys take place. Schrooten et al (2016) explore migrations amongst Brazilians living in Europe, arguing that they live in mobility as opposed to migration, moving between locations and legal statuses. This example usefully highlights that migration journeys do not act as an event in time but are constantly evolving and changing. Journeys therefore act as means through which we can understand migration as a process, where the 'embodied efforts, emotions and frictions that are inherent parts' of immobility/mobility are highlighted (Schapendonk and Steel, 2014, p. 268). It shows that mobility is both ongoing and fragmented, with the destination not always 
reached, or even known. This ongoing and fragmented understanding of mobility fits with a profile associated with young people in international schools, who may experience multiple migrations throughout their childhood. For these young people, the periods that they spend in international schools may be thought of as a period of temporary immobility as part of a longer trajectory of continuing to move. For example, they may accompany their parents to another location, or move on to a different country for higher education. As such they may not have a final destination, with the concept of the journey capturing that their mobility is ongoing.

The dual focus on the movement through space and time means that we can extend the notion of the journey into thinking about youth transitions. Connected to a lifecourse perspective, youth transitions have been theorised as way through which to understand the movement of young people through time, a way in which to understand the steps taken towards adulthood (Punch, 2002, 2015; Worth, 2009; Jeffrey, 2010; Tse and Waters, 2013). In geography, the movement of time is closely associated with space and place, with calls to examine 'the significance of place in the unfolding of life transitions' (Hörschelmann, 2011, p. 378). For example, Pelikh and Kulu (2017) discuss the residential mobility of young people away from their parental home as a youth transition. However, a linear understanding of time is subject to critique within this literature. Instead, there has been a shift towards the concept of 'becoming' (Worth, 2009; Holloway, Holt and Mills, 2018). This literature draws upon theorisations by Grosz, who sees time as processual (Worth, 2009). Becoming therefore illustrates how time is something that is navigated, felt and experienced. Worth (2009, p1052), draws upon Horton and Kraftl (2006) to argue that this means we see becoming as involving a 'scrumpling, folding, and pleating of space-time.' That is, becoming involves understanding the intersections between 
time and space, through which young people navigate. Being, as someone's current life, is seen to connect relationally to becoming, their future life. In this paper, I look at how young people in international schools represent past becomings to their current beings.

Becoming highlights that transitions are an ongoing process, subject to 'ruptures and discontinuities' as opposed to a clear linear process (Hörschelmann, 2011, p. 378). This mirrors how the journey has been used within research on mobilities. However, within geographies of youth, becoming has rarely been examined as a journey. The volume 'Movement, Mobilities and Journeys,' in the Springer Collection on Geographies of Children and Young People has sought to 'open up debate and understandings about the movement and mobility of children and young people' (Laoire and White, 2017, p. v), but contains little on how the journey is theorised. Farmer's (2017) chapter is an exception. She uses the lens of the mobile journey arguing that 'childhoods, movement and belongings are closely intertwined' (p251). For her research in Canadian schools, she asked young people to complete silhouette portraits, whereby they highlighted which parts of them connected to languages and cultures. Farmer (2017) therefore uses the mobile journey as a way through which to understand how young people related to the global world, and how this changes as they navigate through school. As such, we can see the journey as a way to explore the transitions of young people in international schools as becoming, to see the role of both time and space on the characters designed.

This focus on journeys and becomings therefore allows us to explore the spacetimes of the global as designed by young people in international schools. Exploring how the characters move through spaces and time allows us to understand how they represent global mobility, and how global mobility impacts and changes the 
characters that are designed. As figures of the global, the characters act as representations of 'nodes of material connections to places near and far - nodes that are embodied, perceiving, acting, expressing, connected with other humans and with objects' (Ansell, 2009, p. 199). Ansell (2009) examined how the geographies of children and youth had focused on local engagements at the exclusion of understanding the influence of the global on young lives. She argues that we need to use flat ontologies to examine the geographies of children and youth, ones where scales such as the local and global are not placed in hierarchies with one another. This paper utilises this idea. An understanding of moving through offered by journeys and becomings helps us understand the influence of global and local connections on the characters designed, an approach which sees these scales as interwoven.

However, the characters act as more than just representations of global mobility. Although these are not direct expressions of identity, we can see the figures of the global as representations of experience. The representations of the figures of the global are also the experiences, practices and embodiment of mobility—-the ways in which we 'inhabit' it (Cresswell, 2006). To design the characters in the cartoons, a selection could be made from an option of ages: adult, teen, kids. Despite the presence of multiple characters in some cartoons, it was clear that the designers were depicting themselves, for example, a majority of the cartoons utilised young people as their characters. Research in migration more generally examines migration at the scale of the body, or what Dunn (2010) describes as 'embodied transnationalism' where attention is paid to bodily practices. Exploring both the representations of bodies and the bodily practices of the characters provides a means to understand how the figures of global act as representations of how 
internationally mobile young people feel about their global mobility through space and time. The paper will now look at the methodology used to explore this.

\section{Methods}

The paper draws upon innovative participatory research with 68 young people aged between 13 and 17 in two international schools in England in January/February 2017 where they were asked, as part of an hour-long class, to design a cartoon to the title of 'what I think global citizenship means.' The schools both offered the American and International education system and had global citizenship embedded in their school ethos. The cartoon task was followed by the participants writing a description as to why they designed the cartoon in that way. This was part of a larger project that sought to examine the different meanings ascribed to global citizenship from young people in different school settings. These cartoons were produced using online software StoryboardThat, which enables fully poseable characters, textboxes and backgrounds and therefore requires no artistic ability. Example cartoons are presented as figures 1, 2 and 3 below.

Designing cartoons was utilised as method for three reasons. First, as global citizenship is a contested concept, the drawing of cartoons enabled these young people to reflect on what this could be as opposed to asking them to define it as part of their identity. Even though the research was not directly asking participants about their experiences of mobility, it enabled the young people to represent motifs of global mobility in their own terms. Acting as an extension of photo-elicitation methods, the cartoons enabled young people to illustrate change by using multiple frames, an approach which lends itself to biographical research approaches. 
Second, within research on children and young people, the use of participatory methods is now well established (Pimlott-Wilson, 2012). The use of participatory visual methods gives participants 'a clear and central role in the research process' (Rose, 2016, p. 316) where participants can act as knowledgeable subjects. These tropes about participation feed into the third reason that cartoons were utilised. The schools involved wanted the research to take place as part of a classroom setting over an hour. This meant that they wanted the opportunity for all the young people in the class to be able to take part. In one international school, the activity took place as part of two-year group personal and social development class of between 50 and 70 students. In the second school, the research took places in student's Theory of Knowledge or Research Project class of 10 to 25 students over 5 sittings. The schools asked for opt-in parental permission to take part in the research and for the young people to provide their assent. Where no parental permission or assent was granted, the cartoons were deleted before analysis.

Analysis was conducted following Rose's (2016) guide to analysing images as research data. She suggests starting with a content analysis to 'get a sense of what they show' (Rose, 2016, P325). Repetitions of images and ideas were examined in the cartoons, including whether the cartoons depicted single or multiple characters, their body characteristics (age, gender, race), the type and location of scenes shown in the cartoons. Using both the cartoons and their descriptions, codes were then derived using discourse analysis that looked at the iconography of the depictions in the cartoons (c.f. Rose 2016). Although the relationship between global mobility and global citizenship has been subject to critique in the social sciences, these young people both illustrated and articulated this connection. Although six key themes from the research emerged, this paper focuses on the ways in which characters were 
used to depict the global (as opposed to citizenship)—mobility and diversity of community.

As part of their assent form, the young people who took part in the research could choose to highlight their nationality/nationalities, age and gender. Participants described themselves as being 'from' all over the world, but $49 \%$ cited European nationalities and $26 \%$ North American. Nationality, age and gender had no impact upon the way in which the young people represented global mobility. Pseudonyms are used throughout and the respondent's nationalities are not disclosed in the paper to preserve anonymity.

\section{Figures of the Global}

The cartoons designed by the young people in international schools presented two types of characters. The first of these was a solitary character, one who undertook a journey through time and space. The second were cartoons that utilised a group dynamic, whereby the group collectively changes in response to difference. Looking at these two types of figures of the global together, this section will firstly examine the spaces of the global that these young people move through. Secondly, the section will look at the influence of space-time on the figures of the global, looking at how global mobility and difference become felt.

\section{Spaces of the Global}

The concept of the journey has been utilised to explore the spatial and temporal fragmentation of migration. Exploring representations of this mobility journey for young people enables us to understand the valorisation of certain spaces in their

global journeys. Research on tourist mobilities examines the entanglements between 
people, objects and ideas that shape the meaning and experiences of these movements. For example, Urry and Larsen (2011) examine the tourist gaze as a performance that orders, shapes and classifies, rather than reflects the world' (p2); a gaze which is intertwined with the experience of travel. The gaze is a way through which places are represented, which influences the ways in which people move through these spaces. Connecting with wider research on visual cultures (Crang, 2003) locations are imbued with meaning, 'inscribed with specific imaginative geographies' (Urry and Larsen, 2011, p116), which act as referents for certain ideas and values. These representations reflect mobility through time as a well as space.

We can see this type of imaginative geography of location in the cartoons that the young people in international schools designed. In the cartoons, places could be selected from 'scenes' which included town, home, school, transportation, country \& rustic, outdoors, history \& mythical and futuristic. These representations of location 'frame the places that they visit as containing experiences' (Deforges, 1998, p.175). Drawing upon the Tourist Gaze, the scenes in the cartoons are a way difference is depicted to 'features of landscape and townscape which separate them off from everyday experience. Such aspects are viewed because they are taken to be in some sense out of the ordinary' (Urry and Larsen, 2011, p. 4). Most cartoons that were designed around a single character depicted this individual travelling to different destinations around the world-a journey through space. The character in these cartoons represents tropes of the traveller, where the character witnesses' different cultural environments. For example, Logan, designed his cartoon to show 'a person being able to access all over the world' (15, North American). The locations that the blonde character is looking at are tourist attractions in Paris, New York and Beijing. As we only see the back of the boy in the cartoon, he is consuming these 
locations. Other cartoons do not explicitly place the background scenes in their cartoons, but use different environmental settings: an icescape, the jungle or the desert. For example, the three scenes in Anna's cartoon (14, European) show a girl looking different environments: a Nordic scene with two people on a pier; a desert scene with an Arab man, Muslim woman and Sikh man; and an American cityscape with an elderly couple and a dog. She describes her cartoon as showing 'a girl travelling to different places and realizing how there are so many different cultures and environments that are very unique.'

The locations through which the solitary figure of the global travels are designed to be as different from each other as the cartoon software will allow, 'unique' or out of the ordinary from one another. These background scenes act as ways in which places are actively produced as Other. They are selected to show a variety of places and in doing so, actively produce Europe, the Americas and Asia as being culturally different from one another. This becomes a way in which the global is ordered for these young people - it is not the flattening of the world, but how difference is essentialised between locations. Difference becomes folded into distance, with the cityscape produced as different from natural or traditional landscapes. In their journey, the figure of the global experiences difference through travelling through essentialised difference. The character collects different places through their mobility, where 'Difference is defined by the traveller, as something that can be known, understood and experienced through travel' (Deforges, 1998, 178-9).

The other space represented by the young people in cartoons was a space inhabited by a community of figures. These cartoons represent what the cartoon designers think global communities should look like—communities of people of different races and ethnic backgrounds. This is therefore another way through which difference, in 
this case, cultural difference is essentialised in the cartoons. The character selection could be made through the 'cultural' option in the cartoon software. It presented a multitude of options of clothing that illustrate religious difference (for example, it contains a nun, priest, bishop, orthodox Jewish male and female, a Muslim woman wearing a hijab, abaya or burkha, a Muslim man wearing a kurta or a wakeel, a Sikh man and so on) and cultural difference (from Cossacks, to men wearing sombreros, kilts and women in grass skirts). All these characters could have their skin colours changed (six options, with blank being the default) as well as eye, hair and clothes colour. Maya's cartoon emphasised religious differences in her use of blank characters with different clothing — a Sikh man, woman in a burka, orthodox Jew and a nun. Lukas, a fifteen-year-old European pupil utilises different skin colours to indicate different ethnic backgrounds. He illustrates in three frames multi-racial young people being able to 'make friends everywhere.' The first frame shows a young male befriending a young female in the street of a city; in the second frame another young male asks to join them in a bar, to which they respond, 'we would love to have you with us.' The last frame shows a classroom setting with the young people exclaiming how much they love their new friends.

Difference is essentialised and definitively present in the cartoons with a group of characters. In the marketing of international schools, businesses and other institutions, people from multiple races are often utilised to suggest a global reach. Therefore, in the cartoons, a global community is represented, one which is both inclusive, and illustrative of, visible markers of difference in terms of race or clothing. Through this, the cartoons illustrate a clear expression of Othering. Mia, a fourteenyear-old European pupil shows the formation of a community in more depth. Her 
cartoon shows an interaction between a white young female (perhaps herself) and a black young female wearing Islamic dress. The cartoon is shown in figure 1.

Figure 1 here

Mia frames her cartoon through the idea that 'religion plays a big role in how we interpret other people.' In this cartoon, Mia is telling a story about an Other-a Muslim women. The woman is upset, which is a result of people 'judging her and showing her 'no[w] respect.' In response to this, in the second frame, the white woman responds 'people are suppose[d] to be nice and welcoming to new cultures'- this sets up the idea that people should, as Mia highlights in her description, 'respect each other' despite religious difference. The white female leads the Muslim female into the cafe where other multi-racial cultures are also present-a young male wearing an Asian rice hat, young females in grass skirt and a Buddhist monk. The main character therefore acts as the hero of the cartoon. All of these people are described as also having 'different backgrounds'-by sticking together all of these individual Others become a community of Others.

The community of global figures is a space through which the solitary figure travels through on their migration journey, or rather the community of figures is a collection of the solitary figures of the global. Regardless of how different the places or people really are from one another, they are all represented in the cartoons as being as different from each as possible, with race, religion and culture acting as markers of this difference. Similar to the collection of places in cartoons, these respondents 
show a collection of people from different racial and cultural backgrounds. Therefore, not only are different places mastered, but also cultural differences between people. This clearly illustrates notions of elite cosmopolitanism, where difference is seen to be consumed and collected (Calhoun, 2008; Deforges 1998). However, by looking at how the characters in the cartoons change in response to how the global is represented, we can move beyond understandings of consumption to thinking about adaptation.

\section{Space-Time of the Global}

While the examples above suggest that the Figure of the Global consumes difference through their gaze in different environments or through people, in other cartoons, as opposed to witnessing difference, characters are shown adjusting or changing. This allows us to directly explore the influence of time in migration journeys in two ways. First, the cartoons that depict a solitary figure often depict this character growing older, a change that is embodied and felt. Second, the community of figures illustrate one or more of the characters changing their emotional response to difference.

Although asking about transitions over time was not part of the research, it was clear that many of the characters depicted were growing up between the scenes of the cartoon. In this way, the solitary figure of the global illustrated a journey through time as well as through space. Harry showed this, with his character travelling to different historical periods 'adapting to different countries and religions around the world' (15, North American). This cartoon is shown in figure 2.

Figure 2 here. 
The main character in his cartoon, a white boy wearing the same clothes, is shown in ancient Greece holding a trident, in the desert with a fallen Sphinx wearing a Keffiyeh; and in front of a Buddhist temple wearing a captain's hat. Similarly, Madison's cartoon utilises a changing bag to highlight adaptation. Her cartoon shows a 'girl growing up in different environments[s] and how she is being exposed to different creatures and settings in each one' (15, North American). This female character, who gets bigger between the frames, is in a desert, jungle and a city park. She shows the way in which she adapts to these different environments, which are devoid of people, through carrying what Madison highlights as the correct bag for each situation, for example, a backpack in the jungle and a briefcase in the city. Objects, in these examples hats and a bag, act as a means by which the character is depicted as adapting to the different environments that they are in. Different environments do not simply act as a backdrop for their lives but are actively seen to change the character. The same character grows older, and alters their practices so that they fit in to their new environment.

Like the solitary figure of the global, by looking at the embodied response to essentialist forms of the difference in the cartoons, we can see how the community of figure characters also undertake a journey. Although the movement through time and space is of a smaller scale than that of global mobility, the characters undergo change. Primarily, this reflects a change in the emotional response to difference. As the literature on the geographies of encounter highlights, the coming together of people is often where difference is felt, realised and experienced (Askins, 2016; Nayak, 2017; Wilson, 2017). Within this, feeling comfortable is key to belonging, shaping how people navigate space and their relationship with Others (Nayak, 2017). The assumed starting point to the difference of the characters shown in the 
cartoons is a form of uneasiness, or discomfort. For the communities of figures, actions are seen to change the feelings of discomfort into that of acceptance of the global groups. For example, Maya, a fifteen-year-old European pupil, has two frames to her cartoon. The first frame shows multi-racial characters in front of a government building, while the second frame shows blank, but multi-ethnic characters on a street. Maya describes her cartoon as showing 'all types of people...coming together to form a happy community. It means to have people of all races and religions and ages to finally agree on one thing they all need, happiness and peace.' Here, the 'coming together' indicates change from an individual to a group. Like the solitary traveller showing the mobility journey of the designer, in these cartoons the international school community was often depicted-the cartoon designers were depicting themselves within the cartoon.

Acceptance is expressed in relation to both the self and other in the cartoon. For example, in Mia's cartoon in figure 1 we see the character being judged because she is different. By being brought into the international group, the character finds a place where her difference is respected, where the characters are 'nice' to and 'respect' others. In this way, the character undergoes a journey towards becoming accepted, despite her religious difference. Amelia, a 16-year old European pupil depicted people in her cartoon of 'different cultures and colours' being in 'the same place without discomfort' - this works on the assumption that the normal person would feel uncomfortable being surrounding by difference. Her cartoon shows young and old, male and female, people with different skin colours, and different religious clothing, in three different urban settings. For Amelia, being global was enacted through a (lack of) emotional response to difference, described as being at 'peace' within diverse communities. The cartoon suggests a change in the affective qualities of 
difference, from discomfort to peace-that the characters not only are accepted despite their difference but accept others despite theirs.

Therefore, the cartoons depict the role of friendships in shaping the experiences of these globally mobile young people, especially in viewing the communities of figures as a collection of solitary figures of the global. In his research on youth transitions with first generation Gujrati students, Patel argues that we need to pay more 'attention to the social relations significant to young people's everyday lives as they move in and through the everyday spaces' (2017, p. 46). That is, although research on youth transitions looks at independence as a marker of growing up, we also need to understand the role that friendship plays in shaping potential selves. Friendship also plays a role in how we understand migrant belonging. As highlighted above, mobility is seen to produce new identities, with friends providing ways through which belonging is produced and navigated (Beech 2019; Robertson, 2018). In looking specifically at the formation of (global) communities, the cartoons highlight the importance of friendship networks to the international school pupils. This resonates with research on Third Culture Kids (TCK)—an identity marker popularised in psychology for children who have experienced frequent global mobility. ${ }^{1}$ (Pollock and Van Reken, 2009; Lijadi and Van Schalkwyk, 2017). Due to their frequent global mobility, this group of youth migrants are seen not to have traditional place-based belonging, something which is seen as an alienating experience (see below on grief). Instead, TCKs find a sense of belonging with people who have a similar background

\footnotetext{
${ }^{1}$ When the assent form was explained to the participants, the nationality option was given as 'state your nationality or nationalities as you feel that they best describe you. You can put as many as you like, or none at all. For example, you could put Korean, TCK and Finnish.' Many international schools, including the schools in which the research was carried out in, provide talks to their pupils and their parents about being a Third Culture Kid so this would be a term that many of the participants were familiar with. However, only one respondent described their nationality as a TCK.
} 
(Cranston, 2017). Due to their traditional role in providing education to temporary child migrants, international schools are often linked to TCKs (Tanu, 2016). In this respect, the community of figures within the international schools can be read as the formation of a community of people who have similar backgrounds. Instead of finding belonging to a community of people who look like them, they find belonging to people who have had similar experiences to them.

\section{Space-Times of Young People's Mobility}

By looking at the journey as a movement through time and space, we can see how the figure of the global changes and adapts to different cultural environments. The journeys that the designers of the cartoons in this study have designed illustrate a movement through places and people, a collection of difference that changes the character. This is the gaining of an experience of negotiating difference, which is often read as the accumulation of cultural capital. However, we can see two key divergences by looking at their becomings/journeys through time and place.

First, in Worth's (2009) research on becomings, she highlights how her respondents discussed 'fateful moments' which had an impact on their self-image in relation to the world around them. However, the growing up of the figures of the global between places suggests a more ordinary and mundane understanding of the experience of different cultures. The character does not undergo fundamental change, their bag or hat is often the only way in which change is expressed. The mundane way through which adaptation to change is depicted within the cartoons suggests therefore that for many young people in international schools these are not 'fateful' moments, they are an ordinary part of their childhoods. As suggested above, this is counter-intuitive to research on young people's international experiences which suggests that these 
are extraordinary. Their global mobility was presented as matter of fact as opposed to a rupture.

Second, by considering the embodiment of the figures of the global, there was little direct celebration of the journey through different places. Although not all characters displayed loss or grief in the same way, the use of the solitary character suggests that for many of these young people, global mobility as a child is a lonely experience, even though these young people tend to move as part of a family unit. By looking at how the characters in the cartoons can be embodied, therefore we can also clearly see how growing up in different countries is not an experience which is celebrated. However, in a minority of cartoons, there were clear displays of frustration and grief associated with growing up global. These cartoons illustrated a disconnect between time and space in the migration journey, which, drawing upon the transition literature illustrates the multiplicity, changeability and instabilities of becoming (Worth, 2009). For example, as figure 3 shows, the character in Emma's cartoon (15, North American) is 'a young girl having to move around the world to different countries.' The use of the word 'having' here suggests unwillingness on the characters part.

Figure 3 here.

The first frame shows her on an airplane, with a suitcase, thinking that she misses her friends. The second frame has the same character, but older and with a different coloured suitcase, on a suburban street thinking 'not again.' In both frames, someone out of shot is saying 'welcome to your new home' - the character is 
detached from decisions about mobility. Emma illustrates the frustration of having to move, about having decisions made on her behalf. This suggests a lack of feeling of agency, a feeling of being stuck in time in terms of her family's decision to move forward in their migration journey. This cartoon therefore is a clear example of how time is felt by young people, as well as experienced (c.f. Worth, 2009).

On the other hand, the character in the cartoon designed by Kris, a seventeen-yearold European, embodies loss. In the first frame, he is running in front of a city-scape with his dog. In the second frame, he is running in San Francisco with a new dog. In the last frame, he is outside a school building, with a new dog which is barking and facial hair. Kris describes the transition as 'I'm moving countries...I was happy at first and running, but then I have facial hair and im standing and my dog is angry at me for being sad.' The difference in clothes and hairstyles between the frames shows that the character is changing between locations, the development of facial hair clearly suggests that the character is maturing into adulthood. The sadness that are caused by the journeys of the solitary traveller illustrate some of the characteristics associated with Third Culture Kids, who grieve the lack of a national identity (Cranston, 2017; Sander, 2016; Lijadi and Van Schalkwyk 2017). The cartoon by Kris clearly illustrates the grief of his character's migration journey-the pose of the character is sad, and the death of his dog between frames suggests a loss of close relationships as he moves between locations. In this respect, his mobility through space can be understood as a 'rupture' (Hörschelmann, 2011), a movement away from one future (a time-space), towards the making of a new one. Therefore, unlike most of the other cartoons, it depicts a 'fateful moment' where Kris's lifecourse changes, one where the moving to a different place means that the identity of Kris' character changes-the multiplicity of becoming. 


\section{Conclusions}

This paper has examined how global mobility in childhood is represented by young people in international schools through characters in cartoons. The paper has analysed these characters as being the representation or materialisation of ideas about the global, the characters can therefore be seen as figures of the global. Exploring the characters in the cartoons as figures of the global has enabled, first, an appreciation of the dual role of time and space by examining how the characters undergo a journey. The paper has argued that these characters represent becomings, they are visual narratives of the designer's past and present. However, thinking about how the characters change over time enables us to see what growing up global means to these young people, we see the characters adapting, changing and growing up in among their engagement with the global. For example, the cartoons show the characters finding a community of people where they are both accepted and accept others for their difference. Although the research wasn't asking the respondents directly about identity, the cartoons articulate global identities in terms of accepting communities, different places, and multiple homes. Therefore, by looking at the characters designed in the cartoons as figures of the global, the paper has shown that these figures tell us about the ways in which mobility and cultural difference is felt and experienced over time by these young people.

Second, using figures of the global has enabled us to explore the influence of mobility on the lives of international school pupils, without valorising this as a distinct or different experience. For many young people in international schools, global mobility is not an experience which differentiates them from others around them. Cultural differences are emphasised, experienced, adapted to, but this is a normal 
part of their lifecourse. It is only a minority of cartoons that present global mobility as a discontinuity or fateful moment (Worth, 2009). Exploring how young people represent the global as cartoon characters and landscapes allows us to explore their interpretation of what the global looks and feels like at the scale of their everyday lives. Horton and Kraftl (2006) arguing for a renewed attention to the body and bodily practices within children's geography suggest that this would reinvigorate an interest in the mundane and ordinary. However, this paper illustrates the importance of understanding the ordinary from our participants perspective. For some groups of young people, global mobility is not exceptional, but rather an ordinary experience.

Therefore, while international school pupils can be considered a distinct population, understanding the experiences of global mobility from a population where mobility is ordinary highlights two ways we can advance research on global mobility and youth more generally. First, we need to develop theory on global mobility that reflects a generation on the move (Robertson, Harris and Baldassar, 2017). Part of this involves offering different narratives about the experiences of global mobility itself, which embrace the messy complexities of the differential role that global mobilities play in different young people's lives. For example, accounts of youth mobility framed through Bourdieu, often present this as an exceptional experience that can be collected and therefore possessed for future social mobility. Questions of privilege derive from important work that considers differential access to these mobilities, whether it be volunteering or studying, and how that translates into future advantage (Prazeres, 2018). Using this line of analysis, we can read global mobility as a normal experience among international school pupils as way in which privilege reproduces itself, through a reading of the cartoons which display an elite form of cosmopolitanism. Future research with young people from international schools 
could explore whether the experience of global mobility as normal comes to act as a form of distinction in their future lifecourse. To reflect a generation on the move, however, discussions about distinction would need to consider the influence of class, gender and race as opposed to simply ascribing this in relationship to mobility.

However, this paper has argued that for these young people in international schools, their or their classmate's global mobility, is not a distinctive experience for them at the present. The mundane representations of their engagements with the global suggest that this is something they see as everyday. This has wider implications for how the identities of mobile people can be understood, ones where migration is not seen as a rupture. By not focusing on mobility as exceptional, we can challenge migrant exceptionalism (Hui, 2016), an idea that a person's migrant status is the defining part of their lives and begin to look at other aspects of the relationship between mobility, youth and identity. This would involve questioning whether other groups of young people view their engagements with the global through their mobility in similar ways to international school pupils, or whether these engagements can be read as a form of internalised privilege. More broadly, however, by discursively framing that global mobility can be a normal experience in childhood, we can contribute to challenging Anglo-American discourse that theoretically produces migration an extraordinary or exceptional experience both in people's lives and between people's lives (Hui, 2016, Glick Schiller and Salazar, 2013).

\section{References}

Cheung Judge, R., Blazek, M., Esson, J., Introduction to Special Issue.

Ansell, N. (2009) 'Childhood and the politics of scale: Descaling children's 
geographies?', Progress in Human Geography, 33(2), pp. 190-209. doi:

10.1177/0309132508090980.

Askins, K. (2016) ‘Emotional citizenry: everyday geographies of befriending, belonging and intercultural encounter', Transactions of the Institute of British Geographers, 41(4), pp. 515-527. doi: 10.1111/tran.12135.

Baillie Smith, M. and Laurie, N. (2011) 'International volunteering and development: global citizenship and neoliberal professionalisation today', Transactions of the Institute of British Geographers, 36(4), pp. 545-559. doi: 10.1111/j.14755661.2011.00436.x.

Barker, J. et al. (2009) 'The Road Less Travelled - New Directions in Children's and Young People's Mobility', Mobilities, 4(1), pp. 1-10. doi:

10.1080/17450100802657939.

Beech, S. (2019) The Geographies of International Student Mobility Spaces, Places and Decision-Making. Palgrave.

Bunnell, T. (2016) 'Book review: Elite education: International perspectives', Journal of Research in International Education, 15(2), pp. 175-178. doi: $10.1177 / 1475240916659723$.

Calhoun, C. (2008) 'Cosmopolitanism in the modern social imaginary', Daedalus, 137(3), pp. 105-114. doi: 10.1162/daed.2008.137.3.105.

Cheung Judge, R. (2017) ‘Class and global citizenship: perspectives from non-elite young people's participation in volunteer tourism', Tourism Recreation Research. doi: $10.1080 / 02508281.2017 .1303894$. 
Crang, M. (2003) 'The Hair in the Gate: Visuality and Geographical Knowledge', Antipode, 35(2), pp. 238-243. doi: 10.1111/1467-8330.00321.

Cranston, S., Lloyd, J. (2019) Bursting the Bubble: Spatialising safety for privileged migrant women in Singapore, Antipode, 51(2) 478-496.

Cranston, S. (2017) Self-Help Books and the Surfacing of Identity: Producing the Third Culture Kid as Comfort, Emotion, Space, Society, 24 27-33.

Cresswell, T. (2006) On the move: mobility in the Western World. Routledge. doi: 10.1017/CBO9781107415324.004.

Dobson, M. E. (2009) 'Unpacking children in migration research', Children’s Geographies, 7(3), pp. 355-360. doi: 10.1080/14733280903024514.

Farmer, D. (2017) 'Children and Youth's Mobile Journeys: Making Sense and Connections within Global Contexts', in Laoire, C. N. and White, A. (eds) Movement, Mobilities and Journeys. Singapore: Springer Reference, pp. 245-270.

Grimshaw, T. and Sears, C. (2008) "Where am i from?" "Where do i belong?": The negotiation and maintenance of identity by international school students', Journal of Research in International Education, pp. 259-278. doi: 10.1177/1475240908096483.

Hayden, M. (2011) 'Transnational spaces of education: The growth of the international school sector', Globalisation, Societies and Education, 9(2), pp. $211-$ 224. doi: $10.1080 / 14767724.2011 .577203$.

Hayden, M. C., Rancic, B. A. and Thompson, J. J. (2000) 'Being International: Student and teacher perceptions from international schools', Oxford Review of Education, 26(1), pp. 107-123. doi: 10.1080/030549800103890. 
Holloway, S. L., Holt, L. and Mills, S. (2018) 'Questions of agency: Capacity, subjectivity, spatiality and temporality', Progress in Human Geography. doi: $10.1177 / 0309132518757654$.

Hopkins, P. and Alexander, C. (2010) 'Politics, mobility and nationhood: upscaling young people's geographies: introduction to Special Section', Area, 42(2), pp. 142144. doi: 10.1111/j.1475-4762.2010.00949.x.

Hörschelmann, K. (2011) 'Theorising life transitions: Geographical perspectives', Area, 43(4), pp. 378-383. doi: 10.1111/j.1475-4762.2011.01056.x.

Horton, J. and Kraftl, P. (2006) 'What else? some more ways of thinking and doing “children”s geographies", Children's Geographies, 4(1), pp. 69-95. doi: $10.1080 / 14733280600577459$.

Hui, A. (2016) 'The Boundaries of Interdisciplinary Fields: Temporalities Shaping the Past and Future of Dialogue between Migration and Mobilities Research', Mobilities, 1(11), pp. 66-82. doi: 10.1080/17450101.2015.1097033.

Jeffrey, C. (2010) 'Geographies of children and youth I: eroding maps of life', Progress in Human Geography, 34(4), pp. 496-505. doi: 10.1177/0309132509348533.

Jones, A. (2011) 'Theorising international youth volunteering: training for global (corporate) work?', Transactions of the Institute of British Geographers, 36(4), pp. 530-544. doi: 10.1111/j.1475-5661.2011.00433.x.

King, R. and Raghuram, P. (2013) 'International Student Migration: Mapping the Field and New Research Agendas', Population, Space and Place, 1 March, pp. 127137. doi: 10.1002/psp.1746. 
Kong, L. (2013) 'Balancing spirituality and secularism, globalism and nationalism: the geographies of identity, integration and citizenship in schools', Journal of Cultural Geography, 30(3), pp. 276-307. doi: 10.1080/08873631.2013.834120.

Laoire, C. N. and White, A. (2017) Movement, Mobilities, and Journeys. Edited by C. Ni Laoire, A. White, and T. Skelton. Singapore: Springer Reference. doi: 10.1007/978-981-4585-93-4.

Lijadi, A. A. and Van Schalkwyk, G. J. (2017) ‘Place identity construction of Third Culture Kids: Eliciting voices of children with high mobility lifestyle', Geoforum, 81, pp. 120-128. doi: 10.1016/j.geoforum.2017.02.015.

Lorimer, J. (2010) 'International conservation "volunteering" and the geographies of global environmental citizenship', Political Geography, 29(6), pp. 311-322. doi: 10.1016/J.POLGEO.2010.06.004.

Mainwairing, C. and Brigden, N. (2016) 'Beyond the Border: Clandestine Migration Journeys', Geopolitics, 21(2), pp. 243-262. doi: 10.1080/14650045.2016.1165575.

Nayak, A. (2017) 'Purging the nation: race, conviviality and embodied encounters in the lives of British Bangladeshi Muslim young women', Transactions of the Institute of British Geographers, (Fortier 2008). doi: 10.1111/tran.12168.

Patel, V. (2017) 'Parents, permission, and possibility: Young women, college, and imagined futures in Gujarat, India', Geoforum, 80, pp. 39-48. doi: 10.1016/j.geoforum.2017.01.008.

Pelikh, A. and Kulu, H. (2017) 'Short- and long-distance moves of young adults during the transition to adulthood in Britain', Population, Space and Place. WileyBlackwell, p. e2125. doi: 10.1002/psp.2125. 
Pimlott-Wilson, H. (2012) 'Visualising children's participation in research: Lego Duplo, rainbows and clouds and moodboards', International Journal of Social Research Methodology, 15(2), pp. 135-148. doi: 10.1080/13645579.2012.649410.

Pollock, D. C. and Van Reken, R. E. (2009) Third culture kids : growing up among worlds. Nicholas Brealey Pub.

Prazeres, L. (2018) ‘Unpacking distinction within mobility: Social prestige and international students', Population, Space and Place. Wiley-Blackwell, p. e2190. doi: 10.1002/psp.2190.

Punch, S. (2002) 'Youth transitions and interdependent adult-child relations in rural Bolivia', Journal of Rural Studies, 18(2), pp. 123-133. doi: 10.1016/S07430167(01)00034-1.

Punch, S. (2015) 'Youth transitions and migration: negotiated and constrained interdependencies within and across generations', Journal of Youth Studies, 18(2), pp. 262-276. doi: 10.1080/13676261.2014.944118.

Robertson, S. (2018) 'Friendship networks and encounters in student-migrants' negotiations of translocal subjectivity', Urban Studies, 55(3), pp. 538-553. doi: 10.1177/0042098016659617.

Robertson, S., Harris, A. and Baldassar, L. (2017) 'Mobile transitions: a conceptual framework for researching a generation on the move', Journal of Youth Studies, pp. 1-15. doi: 10.1080/13676261.2017.1362101.

Rose, G. (2016) Visual methodologies: an introduction to researching with visual materials. Fourth. London: SAGE Publications. 
Salazar, N. B. (2017) 'Key figures of mobility: an introduction’, Social Anthropology, 25(1), pp. 5-12. doi: 10.1111/1469-8676.12393.

Sander, M. (2016) 'Passing Through Shanghai: Ethnographic Insights into the Mobile Lives of Expatriate Youths'. Heidelberg University Publishing. doi: 10.17885/HEIUP.48.42.

Schapendonk, J. et al. (2018) 'Re-routing migration geographies: Migrants, trajectories and mobility regimes', Geoforum, June. doi:

10.1016/j.geoforum.2018.06.007.

Schapendonk, J. and Steel, G. (2014) 'Following Migrant Trajectories: The Im/Mobility of Sub-Saharan Africans en Route to the European Union', Annals of the Association of American Geographers, 104(2), pp. 262-270. doi:

10.1080/00045608.2013.862135.

Schrooten, M., Salazar, N. B. and Dias, G. (2016) 'Living in mobility: trajectories of Brazilians in Belgium and the UK', Journal of Ethnic and Migration Studies. Routledge, 42(7), pp. 1199-1215. doi: 10.1080/1369183X.2015.1089160.

Tanu, D. (2016) 'Going to school in "Disneyland”: Imagining an international school community in Indonesia', Asian and Pacific Migration Journal, 25(4), pp. 429-450. doi: $10.1177 / 0117196816672467$.

Tse, J. K. H. and Waters, J. L. (2013) 'Transnational youth transitions: Becoming adults between Vancouver and Hong Kong', Global Networks, 13(4), pp. 535-550. doi: 10.1111/glob.12014.

Urry, J. and Larsen, J. (2011) The tourist gaze 3.0. SAGE. 
White, A. et al. (2011) 'Children's Roles in Transnational Migration', Journal of Ethnic and Migration Studies, 37(8), pp. 1159-1170. doi: 10.1080/1369183X.2011.590635.

Wilson, H. F. (2017) 'On geography and encounter: Bodies, borders, and difference’, Progress in Human Geography, 41(4), pp. 451-471. doi:

$10.1177 / 0309132516645958$.

Wimmer, A. and Glick Schiller, N. (2002) 'Methodological nationalism and beyond: nation-state building, migration and the social sciences', Global Networks, 2(4), pp. 301-334. doi: 10.1111/1471-0374.00043.

Worth, N. (2009) 'Understanding youth transition as "Becoming": Identity, time and futurity', Geoforum, 40(6), pp. 1050-1060. doi: 10.1016/j.geoforum.2009.07.007. 
Figure 1: Mia's Cartoon
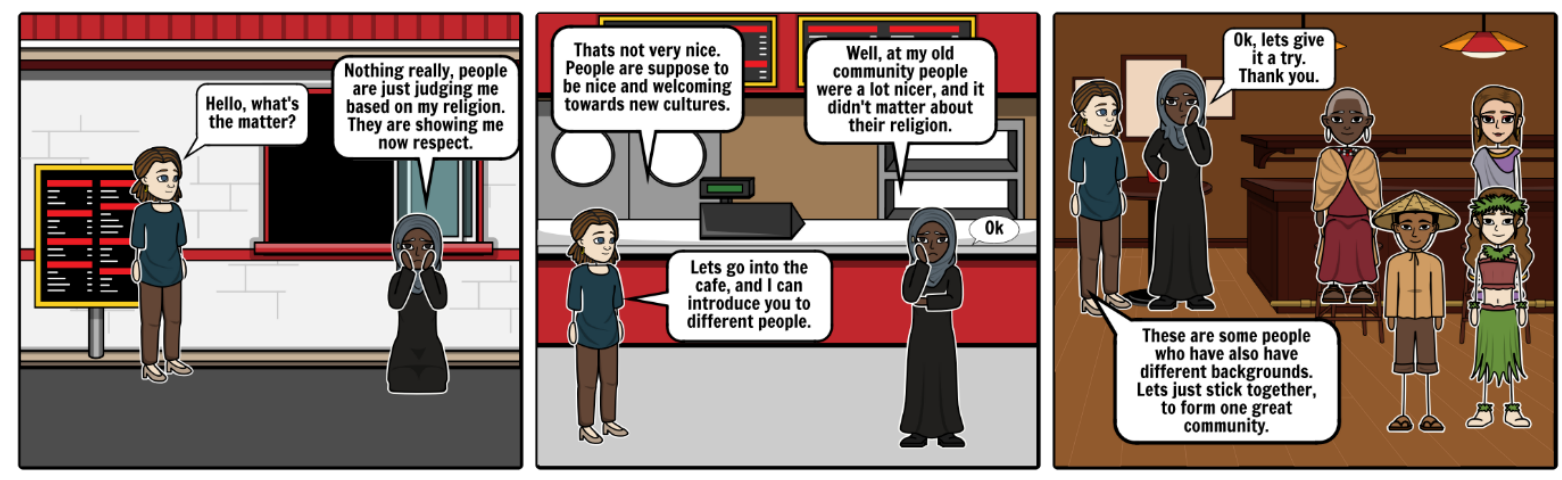

Create your own at Storyboard That

Figure 2: Harry's Cartoon
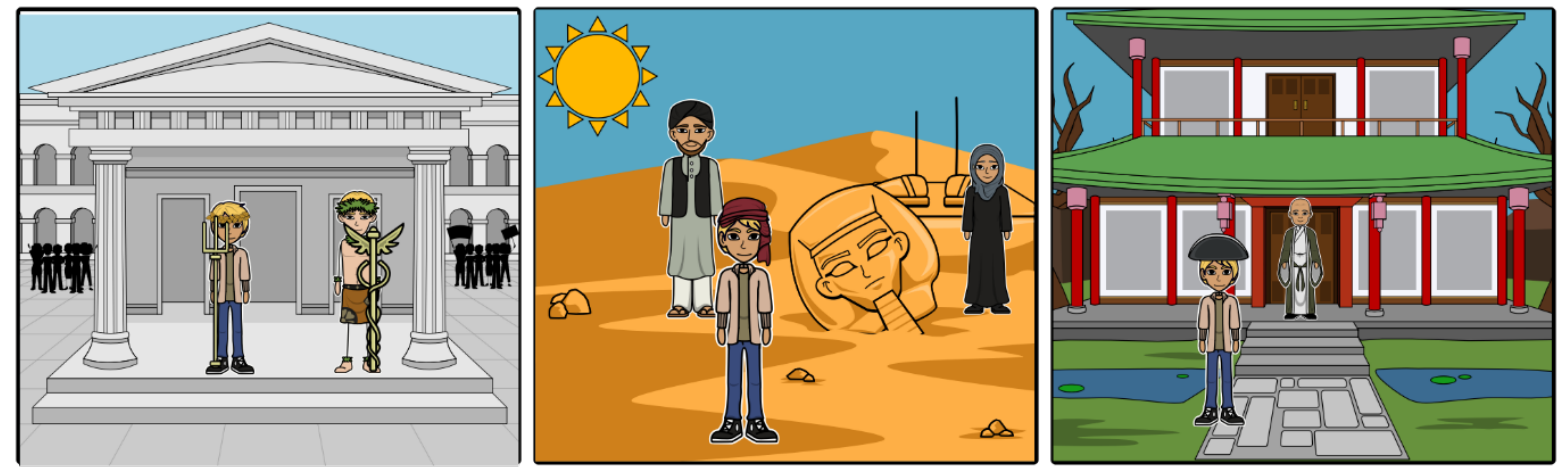

Create your own at Storyboard That

Figure 3: Emma's Cartoon 

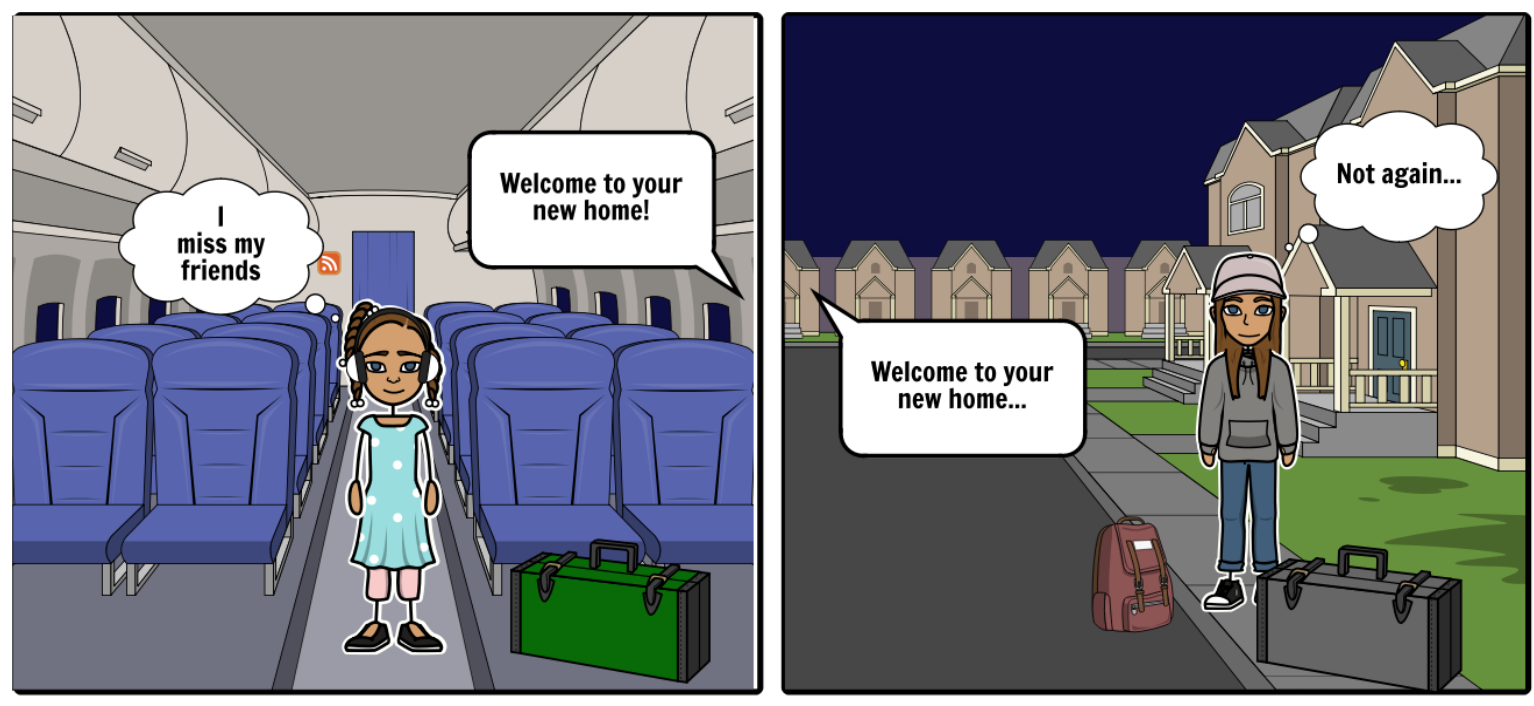

Create your own at Storyboard That 